Ramzi P.1, Solomianyi R.' , Zasieda Y. ${ }^{1,2}$

\title{
COMPLEX TREATMENT OF NON-OBSTRUCTIVE FORMS OF MALE INFERTILITY WITH PLATELET-RICH PLASMA, LOW- INTENSITY PULSED ULTRASOUND AND HUMAN PLACENTA HYDROLYSATE
}

"Men's health" clinic, Kiev, Ukraine;

'Zaporizhzhia State Medical University, Zaporizhzhia, Ukraine

Рамзі П.А. ', Солом'яний Р.І.', Засєда Ю.І. ${ }^{1,2}$

КОМПЛЕКСНЕ ЛІКУВАННЯ НЕОБСТРУКТИВНИХ ФОРМ ЧОЛОВІЧОГО БЕЗПЛІДДЯ ЗА ДОПОМОГОЮ АУТОПЛАЗМИ, ЗБАГАЧЕНОЇ ТРОМБОЦИТАМИ, НИЗЬКОІНТЕНСИВНОГО ІМПУЛЬСНОГО УЛЬТРАЗВУКУ І ГІДРОЛІЗАТУ ПЛАЦЕНТИ ЛЮДИНИ

1«Клініка “Чоловіче здоров'я", Київ, Україна;

2Запорізький державний медичний університет, Запоріжжя, Україна.

Summary

Relevance. Male infertility is basic problem for several medical specialties from genetics and endocrinology to urology and andrology. It's impact on personal quality of life, social functioning and existential aspects of well being and in larger scale on social health is dramatic.

Aim - to develop and test complex treatment model of non-obstructive forms of male infertility with combination of platelet-rich plasma, low-intensity pulsed ultrasound and human placenta hydrolysate.

Methods. The study was based on prospective parallel group design. The study contingent consisted of 46 patients of the "Men's Health Clinic" Kiev, Ukraine, undergoing outpatient treatment for non-obstructive fertility disorders.

Following methods were used: clinical (a standard set of clinical examinations to establish a preliminary diagnosis), laboratory (bacterial seeding of ejaculate for the presence of pathogenic microflora, extended spermogram); serological (evaluations of serum testosterone and luteinizing hormone levels instrumental (sonographic examination of the prostate gland in order exclude prostatic inflammation); statistical.

Results. After the initial complex of examinations study contingent underwent developed treatment protocol: 6 sessions (1 session per week) of local injections of $1 \mathrm{ml} \mathrm{HPH}$ «Laennec»; 6 sessions of local injections of $1 \mathrm{mI} \mathrm{PRP} \mathrm{(1} \mathrm{session} \mathrm{per} \mathrm{week);} 6$ sessions of LIPUS (1 session per week, following HPH and PRP injections); metabolic therapy: «SaluFertil Forte» and «SALUTRIB» 6 weeks daily.

Conclusion. Complex treatment model of non-obstructive forms of male infertility with combination of platelet-rich plasma, low-intensity pulsed ultrasound and human placenta hydrolysate and metabolic therapy with "SaluFertil Forte» and "SALUTRIB», showed significant efficacy in 6-week therapeutic period. Therapeutic effect was found in sperm count in $1 \mathrm{ml}(<0,01)$, sperm aggregation $(<0,01)$ and sperm mobility (group $A+B)(<0,01)$.

Key words: male fertility, asthenozoospermia, platelet-rich plasma, low-intensity pulsed ultrasound, human placenta hydrolysate. 
Relevance. Male infertility is basic problem for several medical specialties from genetics and endocrinology to urology and andrology. It's impact on personal quality of life, social functioning and existential aspects of well being and in larger scale on social health is dramatic [1].

Today the main approaches to male infertility treatment lies in coping with background pathology and normalization of hormonal status of a patient that actually relies on homeostatic principle of further normalization of spermagenesis with the "backup strategy" focused on biotechnology [1].

Last decades there are various studied dedicated to the regenerative medicine potential in application to male infertility. Among them most perspective seems to be platelet-rich plasma (PRP) therapy, low-intensity pulsed ultrasound (LIPUS) therapy and therapy with human placenta hydrolisate [2-9].

PRP therapy proved to be effective in stimulation of neovascularization processes (due to endothelial progenitor cells stimulation and local mesemchymal stem cells activation) and correction of endothelial dysfunction (by optimization of the endothelial and neuronal NO synthases production) which is perspective in improvement of testicular heamodynamics and tissue regeneration $[2,3]$.

LIPUS triggers cellular deformation and induce cellular matrix-cytoplasm signal activation with it transduction to nucleus by cytoskeleton. What results in gene expression of inflammatory molecules such as IL-1 and IL-6, and neural growth-related factors such as BDNF. In ED treatment LIPUS showed effect of induction of extracellular matrix molecular changes and intracellular composition changes in local tissue cells what results in endogenous stem cell activation for local tissue $[5,6]$.

Clinical studies on human placenta hydrolysate (HPH) therapy approved its effects in local tissue regeneration and anti-fibrotic activity by donating various growth factors such as VGEF, FGF, epidermal growth factor (EGF), neural growth factor (NGF), colony-stimulating factors (CSFs) [7].
This complex of treatment methods is perspective for non-obstructive forms of male infertility therapeutic models due to similar aims but different mechanism of action.

Aim - to develop and test complex treatment model of non-obstructive forms of male infertility with combination of platelet-rich plasma, low-intensity pulsed ultrasound and human placenta hydrolysate.

Materials and metods. The study was based on prospective design. The study contingent consisted of 46 patients of the "Men's Health Clinic" Kiev, Ukraine, undergoing outpatient treatment for non-obstructive fertility disorders.

Inclusion criteria
age $18-55$ years;
diagnosis of non-obstructive fertility
disorder
non-critical violations in sperm
morphology
asthenozoospermia I or II $(30 \%-50 \%$
sperm mobility)

\section{Exclusion criteria:}

- - asthenozoospermia III (< 30\% sperm mobility)

- - genetic pathology;

- - infectious pathology;

- - prostate gland inflammation;

- - urinary tract infections;

- - hypogonadism;

- - autoimmune and system pathology;

The study used the following methods: clinical (a standard set of clinical examinations to establish a preliminary diagnosis), laboratory (bacterial seeding of ejaculate for the presence of pathogenic microflora, extended spermogram); serological (evaluations of serum testosterone hormone levels) instrumental (sonographic examination of the prostate gland in order exclude prostatic inflammation); statistical.

Following spermatogram criteria were used (table 1). 
Spermatogram criteria and pathology threshold

\begin{tabular}{|l|c|c|c|}
\hline \multirow{2}{*}{ Criterion } & \multirow{2}{*}{ Pathology threshold } & \multicolumn{2}{c|}{ Contingent } \\
\cline { 3 - 4 } & & Norm. & Pat. \\
\hline Volume (ml) & $<1,5 \mathrm{ml}$ & 40 & 6 \\
\hline Colour & White, slightly gray & 42 & 4 \\
\hline Acidity (pH) & Not fit 7,2-8,0 & 36 & 10 \\
\hline Liquefaction time (min) & Less than 60 & 40 & 6 \\
\hline Viscosity (cm) & $>2 \mathrm{~cm}$ & 39 & 7 \\
\hline Sperm count in 1 ml & $<15000000$ & 6 & 40 \\
\hline Sperm aggregation & present & 23 & 23 \\
\hline Sperm mobility (group A+ B) & $<50 \%$ & 11 & 35 \\
\hline Leucocytes in field & $1-3$ & 0 & 46 \\
\hline
\end{tabular}

The research was carried out in 3 stages:

1. Diagnostic - set of examinations aimed on inclusion and exclusion criteria and establishing the quality of sperm of patients who match study criteria.

2. Therapeutic - the use of developed treatment protocol.

3. Follow-up - analysis of the developed treatment protocol efficacy in 6 weeks after treatment.

Standardized technique for PRP collection was used: $72 \mathrm{ml}$ of blood from the patient's ulnar vein was taken and placed in 8 vacuum tubes with $3,8 \%$ sodium citrate solution. Than 5 min centrifuging at $500 \mathrm{G}$ with the subsequent collection of plasma layer and its following 3 min centrifugation at $1538 \mathrm{G}$ to release $1 \mathrm{ml}$ of lower plasma layer, with its activation by adding $0,1 \mathrm{ml}$ of $10 \%$ calcium chloride solution.

Focused LISWT with following settings was used: $100 \mathrm{mV} / \mathrm{cm}^{2}, 100 \mathrm{~Hz}$ impulse delivery frequency and "activity:pause" ratio equal to $1: 5$
Study results. Initial spermogram data was following:

After the initial complex of examinations study contingent underwent developed treatment protocol:

- 6 sessions ( 1 session per week) of local injections of $1 \mathrm{ml} \mathrm{HPH}$ «Laennec».

- 6 sessions of local injections of $1 \mathrm{ml} \mathrm{PRP}$ (1 session per week);

- 6 sessions of LIPUS: $100 \mathrm{mV} / \mathrm{cm}^{2}$, $100 \mathrm{~Hz}$ impulse delivery frequency and "activity:pause" ratio equal to 1:5 (1 session per week, following $\mathrm{HPH}$ and PRP injections);

- metabolic therapy: «SaluFertil Forte» L-carnitine $(220 \mathrm{mg})$ L-carnitine-acetyl (110 $\mathrm{mg}), \mathrm{L}$-arginine hydrochloride $(320 \mathrm{mg}), \mathrm{L}-$ glutathione (5 mg), Coenzyme Q (10 mg), Vitamin E (30 mg), Folic acid (200 mkg), Zinc (2 mg), Selenium (8,5 mkg) 1 dose/day, 6 weeks daily.; «SALUTRIB» - an extract of steroidal saponins of tribulus plant (Tribulus Terrestris) 1 dose/ day, 6 weeks daily.

Scheme of techniques application presented on figure 1. 

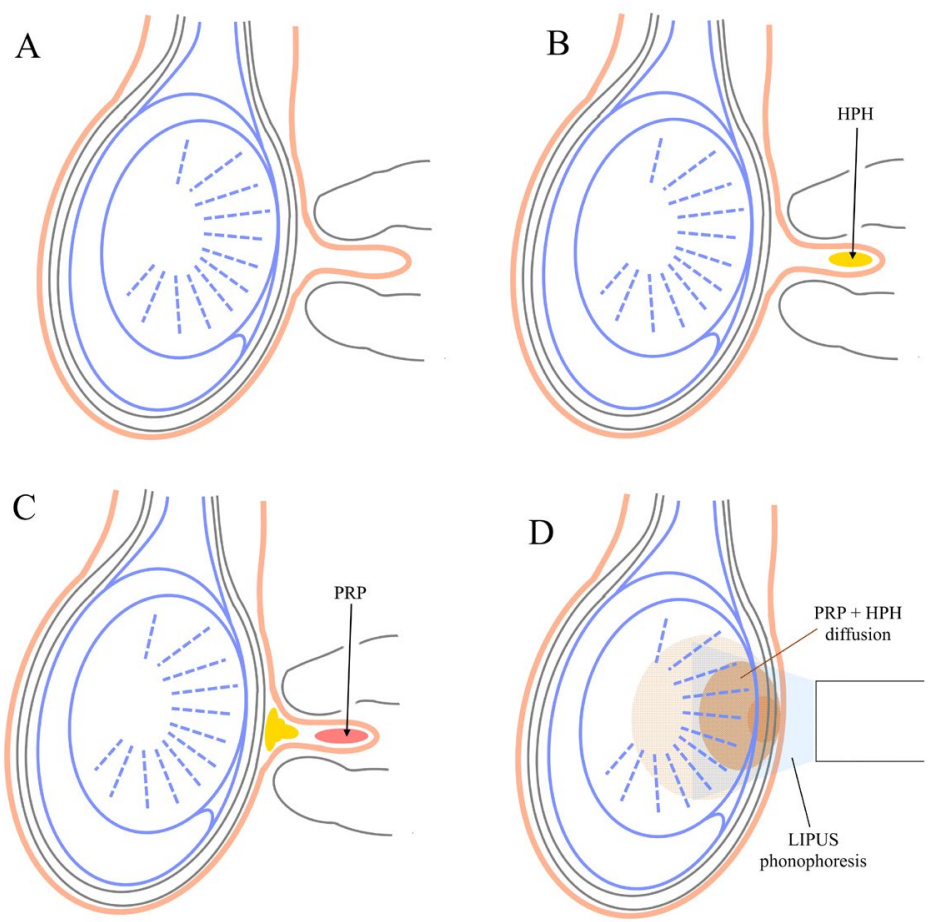

Figure 1. Scheme of techniques application in developed treatment protocol

The follow-up study was performed after 12 weeks of treatment. Spermogram criteria was compared before and after the treatment (table 2 ).

Table 2

Spermogram results comparison

\begin{tabular}{|l|c|c|c|c|c|}
\hline \multirow{2}{*}{ Criterion } & \multicolumn{2}{c}{$\begin{array}{c}\text { Before } \\
\text { therapy } \\
\mathbf{n}=\mathbf{4 6}\end{array}$} & \multirow{2}{*}{$\mathbf{p}\left(\chi^{2}\right)$} & \multicolumn{2}{c|}{$\begin{array}{c}\text { After } \\
\text { therapy } \\
\text { n=46 }\end{array}$} \\
\cline { 2 - 3 } \cline { 5 - 6 } & Norm. & Pat. & & Norm. & Pat. \\
\hline Volume & 40 & 6 & 0,14 & 44 & 2 \\
\hline Colour & 42 & 4 & 0,04 & 46 & 0 \\
\hline Acidity & 36 & 10 & 0,08 & 42 & 4 \\
\hline Liquefaction time & 40 & 6 & 0,14 & 44 & 2 \\
\hline Viscosity & 39 & 7 & 0,54 & 41 & 5 \\
\hline Sperm count in 1 ml & 6 & 40 & $<0,01$ & 29 & 15 \\
\hline Sperm aggregation & 23 & 23 & $<0,01$ & 37 & 9 \\
\hline Sperm mobility (group A + B) & 11 & 35 & $<0,01$ & 28 & 18 \\
\hline Leucocytes & 46 & 0 & - & 46 & 0 \\
\hline
\end{tabular}

According to follow-up study results significant therapeutic effect was found in sperm count in $1 \mathrm{ml}(<0,01)$, sperm aggregation $(<0,01)$ and sperm mobility (group $A+B)$ $(<0,01)$.
Natural pregnancy was registered in 17 patient's couples in 1 year catamnesis observation.

Conclusion. Complex treatment model of non-obstructive forms of male infertili- 
ty with combination of platelet-rich plasma, low-intensity pulsed ultrasound and human placenta hydrolysate with «SaluFertil Forte» and «SALUTRIB» showed significant efficacy in 6-week therapeutic period. Therapeutic effect was found in sperm count in $1 \mathrm{ml}(<0,01)$, sperm aggregation $(<0,01)$ and sperm mobility (group $A+B)(<0,01)$.

\section{REFERENCES}

1. Gorpinchenko I. I., ta in. Choloviche bezpliddya v Ukrayini: statistika ta tendenciyi [Male infertility in Ukraine: statistics and trends], Zdorove muzhchiny. 2012. № 4. P. 132-141.

2. Notarnicola A, Tamma R, Moretti L, Panella A, Dell'endice S, Zallone A, Moretti B. Effect of shock wave treatment on platelet-rich plasma added to osteoblast cultures. Ultrasound Med Biol. 2011 Jan;37(1): 160-8.

3. Hausner T, Pajer K, Halat G, et al. Improved rate of peripheral nerve regeneration induced by extracorporeal shock wave treatment in the rat. Exp Neurol 2012;236:363-70.

4. Wu YN, Wu CC, Sheu MT, Chen KC, Ho HO, Chiang HS. Optimization of platelet-rich plasma and its effects on the recovery of erectile function after bilateral cavernous nerve injury in a rat model. J Tissue Eng Regen Med. 2016 0ct;10(10): E294-E304.

5. Lei H, Xin H, Guan R, et al. Low-intensity Pulsed Ultrasound Improves Erectile Function in Streptozotocin-induced Type I Diabetic Rats. Urology 2015;86:1241.e11-8.

6. Iwabuchi $Y$, Tanimoto $K$, Tanne $Y$, et al. Effects of low-intensity pulsed ultrasound on the expression of cyclooxygenase-2 in mandibular condylar chondrocytes. J Oral Facial Pain Headache 2014;28:261-8.

7. Lee K.H., Kim T.H., Lee W.C., Kim S.H., Lee S.Y., Lee S.M. Anti-inflammatory and analgesic effects of human placenta extract. Nat. Prod. Res. 2011;25(11):1090-100.

\section{PEЗЮME}

\section{КОМПЛЕКСНЕ ЛІКУВАННЯ}

НЕОБСТРУКТИВНИХ ФОРМ ЧОЛОВІЧОГО БЕЗПЛІДДЯ ЗА ДОПОМОГОЮ АУТОПЛАЗМИ, ЗБАГАЧЕНОЇ

ТРОМБОЦИТАМИ, НИЗЬКОІНТЕНСИВНОГО ІМПУЛЬСНОГО УЛЬТРАЗВУКУ І ГІДРОЛІЗАТУ ПЛАЦЕНТИ ЛЮДИНИ

Рамзі П.А.' ', Солом'яний Р.І. ', Засєда Ю.І.1,2 "«Клініка "Чоловіче здоров'я", Київ, Україна;

23апорізький державний медичний університет, Запоріжжя, Україна.

Актуальність. Чоловіче безпліддя - основна проблема кількох медичних спечіальностей, від генетики та ендокринології до урології та андрології. Його вплив на якість життя людини, соціальне функціонування і екзистенційні аспекти благополуччя, а в більш широкому масштабі - на соціальне здоров'я, $\epsilon$ дуже значним.

Meта - розробити і протестувати комплексну модель лікування необструктивних форм чоловічого безпліддя з використанням комбінації ауто плазми, збагаченої тромбоцитами (АЗТ), низькоінтенсивного імпульсного ультразвуку (НІУЗ) і гідролізату плаченти людини (ГПЛ).
Meтоди. Дослідження проведено в проспективному дизайні. Контингент дослідження склав 46 пачієнтів "Клініки «Чоловіче здоров'я» м. Київ, Україна, що знаходяться на амбулаторному лікуванні з приводу необструктивних порушень фертильності.

Використовувалися наступні методи: клінічний, лабораторний; серологічний; сонографічний; статистичний.

Отримані результати. Після початкового комплексу обстежень досліджуваного контингенту було проведено розроблений протокол лікування: 6 сеансів (1 сеанс на тиждень) локальних ін'єкцій 1 мл ГПЛ «Лаеннек»; 6 сеансів місиевих ін'єкцій АЗТ по 1 мл (1 сеанс на тиждень); 6 сеансів НІУз (1 сеанс на тиждень після ін'єкцій ГПЛ і АЗТ); метаболічна терапія: «СалуФертіл Форте» та «САЛУТРІБ» 6 тижнів щодня.

Висновок. Модель комплексного лікування необструктивних форм чоловічого безпліддя комбіначією аутоплазми, збагаченої тромбочитами, низькоінтенсивного імпульсного ультразвуку і гідролізату плаченти людини в умовах призначення метаболічної терапії “СалуФертіл Форте» та «САЛУТРІБ», показала значну ефективність протягом 6-тижневого терапевтичного періоду. Терапевтичний ефект виявлений за кількістю 
сперматозоїдів в 1 мл $(<0,01)$, показником агрегачії сперматозоїдів $(<0,01)$ і рухливості сперматозоїдів (група $A+B)(<0,01)$.

Ключові слова: чоловіча фертильність, астенозооспермія, аутоплазма, збагачена тромбоцитами, гідролізат плаченти людини, низькоінтенсивний імпульсний ультразвук.

\section{PEЗЮME \\ КОМПЛЕКСНОЕ ЛЕЧЕНИЕ \\ НЕОБСТРУКТИВНЫХ ФОРМ МУЖСКОГО \\ БЕСПЛОДИЯ С ПОМОЩЬЮ АУТОПЛАЗМЫ, ОБОГАЩЁННОЙ ТРОМБОЦИТАМИ, НИЗКОИНТЕНСИВНОГО ИМПУЛЬСНОГО УЛЬТРАЗВУКА И ГИДРОЛИЗАТА ПЛАЦЕНТЫ ЧЕЛОВЕКА}

Рамзи П.А. ${ }^{1}$, Соломенный Р.И.', Заседа Ю.И., 1 «Клиника» Мужское здоровье «, Киев, Украина;

23апорожский государственный медицинский университет, Запорожье, Украина

Актуальность. Мужское бесплодие - основная проблема нескольких медицинских специальностей, от генетики и эндокринологии до урологии и андрологии. Его влияние на качество жизни человека, сочиальное функционирование и экзистенциальные аспекты благополучия, а в более широком масштабе - на социальное здоровье, является очень значительным.

Цель - разработать и протестировать комплексную модель лечения необструктивных форм мужского бесплодия с использованием комбинации ауто плазмы, обогащенной тромбоцитами (АЗТ), низкоинтенсивного импульсного ультразвука (НИУЗ) и гидролизата плаценты человека (ГПЛ).
Методы. Исследование проведено в проспективном дизайне. Контингент исследования составил 46 пачиентов "Клиники« Мужское здоровье», г. Киев, Украина, находящихся на амбулаторном лечении по поводу необструктивных нарушений фертильности.

Использовались следующие методы: клинический, лабораторный, серологический, сонографический, статистический.

Полученные результаты. После первоначального комплекса обследований исследуемого контингента был проведён разработанный протокол лечения: 6 сеансов (1 сеанс в неделю) локальных инъекций 1 мл ГПЛ «Лаэннек»; 6 сеансов местных инъекций АЗТ по 1 мл (1 сеанс в неделю); 6 сеансов НИУз (1 сеанс в неделю после инъекций ГПЛ и АЗТ); метаболическая терапия: «СалуФертил Форте» и «САЛУТРИБ» 6 недель ежедневно.

Вывод. Модель комплексного лечения необструктивных форм мужского бесплодия комбинацией аутоплазмы, обогащенной тромбочитами, низкоинтенсивного импульсного ультразвука и гидролизата плаценты человека в условиях назначения метаболической терапии "СалуФертил Форте» и «САЛУТРИБ», показала значительную эффрективность в течение 6-недельного терапевтического периода. Терапевтический эффект обнаружен по количеству сперматозоидов в 1 мл $(<0,01)$, показателем агрегации сперматозоидов $(<0,01)$ и подвижности сперматозоидов (групnа $A+B)(<0,01)$.

Ключевые слова: мужская фертильность, астенозооспермия, аутоплазма, обогащенная тромбочитами, гидролизат плаченты человека, низкоинтенсивный импульсный ультразвук.

\section{AUTHOR'S DATA}

- Ramzi Parviz, physician of "Men's health" clinic", Kyiv.

- Address: Ukraine, Kyiv, st. Lavrska, 4

- Contact number: +380633359708

- E-mail:dr.ramziparviz@gmail.com

- Solomianyi Ruslan,

- physician of "Men's Health" Clinic", Kyiv

- Address: Ukraine, Kyiv, st. Lavrska, 4

- Contact number: +390976500444

- E-mail:glooobal@ukr.net
- Рамзі Парвіз Аріф огли, лікар клініки «Мужское Здоровье», м. Київ

- Адреса: Україна, Київ, вул. Лаврська, 4

- Телефон: +380633359708

- E-mail:dr.ramziparviz@gmail.com
- Рамзи Парвиз Ариф оглы, врач клиники «Мужское Здоровье», г. Киев

- Адрес:Украина, Киев, ул. Лаврская, 4

- Телефон: +380633359708

- E-mail:dr.ramziparviz@gmail.com
- Солом'яний Руслан Іванович,

- лікар клініки «Мужское Здоровье», м. Київ

- Адреса:Україна, Київ, вул. Лаврська, 4

- Телефон: +390976500444

- E-mail:glooobal@ukr.net
- Соломенный Руслан Иванович,

- врач клиники «Мужское Здоровье», г. Киев

- Адрес: Украина, Киев, ул. Лаврская, 4

- Телефон: +390976500444

- E-mail: glooobal@ukr.net 
- Zasieda Yurii

- MD, Urologyst, Andrologyst, PhD, Doctor of Science, CM0 of "Men's Health" Clinic", Kyiv

- Address: Ukraine, Kyiv, st. Lavrska, 4

- Contact number: +390976500444

- E-mail:zasieda@gmail.com
- Засєда Юрій Ігорович,

- д. мед. н., Головний лікар клініки «Мужское Здоровье», м. Київ.

- Адреса: Україна, Київ, вул. Лаврська, 4

- Телефон: +390976500444.

- E-mail: zasieda@gmail.com
- Заседа Юрий Игоревич,

- д. мед. н., Главный врач клиники «Мужское Здоровье», г. Киев

- Адрес: Украина, Киев, ул. Лаврская, 4

- Телефон: +390976500444

- E-mail: zasieda@gmail.com

Стаття надійшла до редакції 14.12.2020 p. У разі виникнення питань до автора статmі, звертайтесь до редакціїжурналу info@ujmh.net 